Recebido: $30 / 10 / 2018$

Aprovado: 23/11/2018

\title{
O segredo das asas: a colaboração fílmica do INCE para a construção de uma mentalidade aeronáutica durante o governo Vargas
}

André Barbosa Fraga ${ }^{1}$

Resumo: Este artigo analisa o filme O segredo das asas, produzido em 1944 pelo Instituto Nacional de Cinema Educativo (INCE), durante o governo Vargas. As décadas de 1930 e 1940 foram marcadas pelo protagonismo mundial do avião. No período, ocorreu a unificação das aviações existentes no Brasil após a criação do Ministério da Aeronáutica. Procurar-se-á demonstrar que, nesse contexto, a película em questão deve ser considerada um importante elemento desenvolvido pelo regime para auxiliá-lo em seu projeto de construção de uma mentalidade aeronáutica.

Palavras-chaves: Instituto Nacional de Cinema Educativo; O segredo das asas; Governo Vargas.

\footnotetext{
${ }^{1}$ Doutor e Mestre pelo Programa de Pós-Graduação em História da Universidade Federal Fluminense (UFF). Bacharel e licenciado em história pela Universidade Federal do Rio de Janeiro (UFRJ). E-mail: <andrebfraga@yahoo.com.br>.
} 
Abstract: This article analyzes the film The Secret of the Wings, produced in 1944 by the National Institute of Educative Cinema (INCE), during the Vargas government. The 1930 s and 1940 s were marked by the plane as protagonist. In the period, there was the unification of the existing aviation in Brazil after the creation of the Ministry of Aeronautics. It will be tried to demonstrate that, in this context, the film in question should be considered an important element developed by the regime in its project of elaborating an aeronautical mentality. Keywords: National Institute of Educative Cinema; The secret of the wings; Government Vargas.

\section{1- Introdução}

Nas décadas de 1930 e 1940, o Brasil passou por transformações profundas em todas as dimensões da vida social: política, econômica e cultural. Sem dúvida, uma das mudanças ocorridas mais significativas e que teve impacto direto nessas três instâncias foi a centralidade alcançada pelo avião. Nesse momento, os aparelhos aéreos, tanto no uso militar quanto no civil, seguindo uma tendência mundial, consolidaram-se como parte do cotidiano da população. O emprego estratégico do setor aéreo civil e militar, como meio de comunicação, de comércio e de defesa, revelou-se uma ação do primeiro governo Vargas (1930-1945) fundamental para a implantação de seu modelo de país, no qual questões-chave, como a unidade nacional, a defesa nacional e a modernidade, seriam melhor alcançadas ao passo que a nação caminhasse em busca da transformação do Brasil em uma potência aérea.

Diante do lugar fulcral que a aviação passou a ocupar, o governo procurou intensificar investimentos públicos e privados no setor por meio da elaboração de um projeto de $E s^{2} a d{ }^{2}$ voltado à construção do que foi chamado na época de uma "mentalidade aeronáutica”. ${ }^{3}$ Ela consistia na tentativa de se expandir a conscientização geral da população a respeito do desenvolvimento da navegação aérea, despertando a união e a contribuição de todos os brasileiros à causa. Ou seja, a campanha tinha por intuito incentivar, de um modo geral, cada cidadão a colaborar da maneira que pudesse.

\footnotetext{
${ }^{2}$ Utiliza-se a noção de projeto no sentido empregado por Gilberto Velho: "conduta organizada para atingir finalidades específicas” (VELHO, 1994: 101).

${ }^{3}$ A expressão apareceu com frequência nas publicações oficiais do regime, sendo um bom exemplo o seguinte artigo publicado em Dos Jornais (RODRIGUES, 1941).
} 
Já nos jovens do sexo masculino, em particular, estimulava-se o interesse de seguirem futuramente alguma das ocupações militares ligadas ao campo aeronáutico.

Durante a década de 1930, as aviações no Brasil estavam divididas e controladas por três ministérios diferentes. O da Viação e Obras Públicas se responsabilizava pela navegação aérea civil, o da Guerra pela aviação do Exército, e o da Marinha pela aviação naval. Essa forma de organização sofreu críticas ao longo do tempo, principalmente após as principais potências mundiais criarem "Ministérios do Ar”, percebendo a necessidade de a aviação militar de seus países ser organizada de maneira independente e centralizada em torno de um único órgão. No Brasil, campanhas pela criação de um ministério responsável pela unificação de todas as aviações se intensificaram a partir de 1935. Uma delas, de ampla repercussão junto à imprensa, foi elaborada por uma comissão composta de aviadores do Exército e da Marinha, liderada pelos tenentes-coronéis Ivo Borges e Armando de Souza Ararigbóia, pelo capitão Antônio Alves Cabral e pelos capitães de corveta Amarílio Vieira Cortez, Luiz Leal Netto dos Reis e Álvaro de Araújo (LAVENÈRE-WANDERLEY, 1975: 213). Os adeptos de um ministério exclusivo para comandar as aviações apresentaram duas justificativas principais: dar uniformidade e trazer economia às atividades da aviação (O RADICAL, 1940: 4).

Contudo, foi durante a Segunda Guerra, após os resultados bem-sucedidos do emprego da aviação nela, que o governo brasileiro ficou estimulado a cogitar efetivamente uma mudança estrutural no setor. Em 1940, Getúlio Vargas juntou a documentação sobre o assunto produzida por civis e militares e a entregou ao então capitão Nero Moura, seu piloto particular, para que este reunisse outros colegas aviadores e formulasse um parecer. Após reuniões com representantes da Aviação Militar, todos com quem conversou se mostraram favoráveis à criação do ministério (MOURA, 1996: 92 e 93). Concomitantemente, o presidente requisitou aos representantes do Exército, da Marinha e do Ministério da Viação e Obras Públicas pareceres favoráveis ou não à medida. O Estado Maior da Armada se apresentou contrário à unificação em memorando remetido ao Conselho de Segurança Nacional. ${ }^{4}$ Já o Exército e o Ministério da Viação e Obras Públicas se mostraram favoráveis à iniciativa. ${ }^{5}$

\footnotetext{
${ }^{4}$ Esse parecer do Estado Maior da Armada pode ser consultado em: Fundo Salgado Filho, R0, caixa 1, pacote 1, doc. 2. Arquivo Nacional.

${ }^{5}$ Para acessar o parecer do Estado Maior do Exército e o ofício do ministro da Guerra Eurico Gaspar Dutra, ver: Fundo Salgado Filho, R0, caixa 6, pacote 15, dossiês 12 e 13. Arquivo Nacional. Por sua vez, os ofícios
} 
No final daquele ano, o chefe de Estado aprovou a proposta de unificação e de criação de um novo ministério encarregado de administrar todas as aviações existentes no país. Dessa forma, em 20 de janeiro de 1941, foi criado o Ministério da Aeronáutica e escolhido para chefiar a Pasta o político gaúcho Joaquim Pedro Salgado Filho. Este aproveitou a "Semana da Asa” de 1941, ocorrida em outubro, para sintetizar em uma frase a meta que havia traçado com o intuito de estimular e desenvolver na população uma mentalidade aeronáutica: "Pilotos para o Brasil, aviões para os pilotos e técnicos para os aviões. Esta é a flâmula aeronáutica”. ${ }^{6}$ Ou seja, para conscientizar a população sobre o assunto e reestruturar a navegação aérea, o novo ministro investiu no aumento do número de pilotos civis e militares (concedendo subvenções aos aeroclubes e às escolas de aviação civil e criando a Escola de Aeronáutica), no crescimento da quantidade de aviões disponíveis para treinamento (estimulando a Campanha Nacional de Aviação, de doação de aviões para treinamento civil, e a construção da Fábrica Nacional de Aviões e da Fábrica Nacional de Motores) e na elevação da proporção de jovens e de militares interessados nas profissões técnicas, como as de engenharia e mecânica para a aviação (fundando campeonatos de aeromodelismo e a Escola de Especialistas de Aeronáutica). ${ }^{7}$ Para colaborar com todas essas ações, a Aeronáutica contou com o auxílio de outros ministérios ou órgãos governamentais. O Instituto Nacional de Cinema Educativo (INCE) foi um deles. Dessa forma, este artigo pretende analisar o filme $O$ segredo das asas, de 1944, demonstrando como ele contribuiu significativamente para a construção, em curso no período, de uma mentalidade aeronáutica.

\section{2- O INCE e a sua finalidade}

No final da década de 1920, intensificou-se no Brasil uma discussão, também presente em outras partes do mundo na mesma época, sobre a possibilidade de utilização do cinema como ferramenta para o desenvolvimento da educação no país. Revistas e jornais passaram a abordar a questão, bem como educadores de prestígio, como, por

com os projetos de autoria do Departamento de Aeronáutica Civil e do Conselho Nacional de Aeronáutica estão depositados em: Fundo Salgado Filho, R0, caixa 6, pacote 15, dossiês 14 e 15. Arquivo Nacional.

${ }^{6}$ A frase está presente na programação da "Semana da Asa" de 1941. Um exemplar desta pode ser encontrado em: Fundo Salgado Filho, R0, caixa 13, doc. 25. Arquivo Nacional.

${ }^{7}$ Para uma análise aprofundada da construção dessa mentalidade aeronáutica e das ações de Salgado Filho em prol dela, ver: FRAGA (2017).




exemplo, os pioneiros da Educação Nova Fernando de Azevedo e Jonathas Serrano. Vários grupos de intelectuais envolvidos nesse movimento buscaram com ele o emprego de técnicas avançadas na educação e a construção de uma identidade nacional através das imagens voltadas à instrução moral, cívica e higiênica da população. Em 1928, Fernando de Azevedo, então diretor do Departamento de Educação do Distrito Federal, deu o primeiro passo ao determinar o uso do cinema como meio educativo no Distrito Federal, tornando-se a primeira iniciativa oficial no Brasil em favor desse gênero cinematográfico. No ano seguinte, ainda na capital da República, Jonathas Serrano organizou a $1^{\mathrm{a}}$ Exposição de Cinematografia Educativa, sendo considerada um dos marcos iniciais desse tipo de cinema no país (ROSA, 2002: 8, 16 e 17).

No ambiente pós Revolução de 1930, o cinema comercial se expandiu consideravelmente, tornando-se uma das alternativas mais populares de lazer nas grandes cidades brasileiras, cujos espectadores lotavam as salas em busca principalmente dos filmes norte-americanos. Na Europa, os regimes nazista e fascista, respectivamente, na Alemanha e na Itália, haviam desenvolvido com êxito órgãos de produção de cinema educativo incorporados à máquina do Estado. Nesse contexto, o cinema passou a ser considerado pelo próprio presidente provisório do Brasil como um veículo privilegiado para a transmissão de ideias políticas e de visões a respeito da identidade nacional, podendo atender justamente aos objetivos do governo de estimular o desenvolvimento intelectual, moral e físico do povo. Inclusive, em discurso proferido no dia 25 de junho de 1934, em manifestação promovida pela Associação Brasileira de Produtores, nos jardins do Palácio Guanabara, Getúlio Vargas revelou toda a sua admiração pela invenção dos irmãos Lumiére, ao anunciar:

Sanear a terra, polir a inteligência e temperar o caráter do cidadão, adaptando-o às necessidades do seu habitat, é o primeiro dever do Estado. Ora, entre os mais úteis fatores de instrução, de que dispõe o Estado moderno, inscreve-se o cinema.

(...)

O cinema será, assim, o livro de imagens luminosas, no qual as nossas populações praieiras e rurais aprenderão a amar o Brasil, acrescendo a confiança nos destinos da Pátria. Para a massa dos analfabetos, será essa a disciplina pedagógica mais perfeita, mais fácil e impressiva. Para os letrados, para os responsáveis pelo êxito da nossa administração, será uma admirável escola.

Associando ao cinema o rádio e o culto racional dos desportos, completará o Governo um sistema articulado de educação mental, moral e higiênica, dotando o Brasil dos instrumentos imprescindíveis à preparação de uma raça empreendedora, resistente e varonil. E a raça



(PPGHIS/UnB) No. 33, Brasília, Ago - Dez 2018 ISSN 2316-1191 
que assim se formar será digna do patrimônio invejável que recebeu (VARGAS, 1938: 187-189).

O ministro da Educação e Saúde Gustavo Capanema, que assumiu a Pasta um mês após esse discurso do chefe de Estado e dez dias depois da eleição de Vargas para a presidência da República pela Constituinte, não demorou muito para começar a pensar na possibilidade de criar um órgão federal, sob seu controle, que atendesse aos objetivos da instrução pedagógica por intermédio do cinema. Para tornar efetivo o projeto, encaminhou ao presidente uma petição requisitando que fosse montada uma comissão instaladora do futuro Instituto Nacional de Cinema Educativo (INCE). Este mostrou-se favorável ao empreendimento, o que permitiu a organização da comissão em março de 1936. Após reunida, sua primeira decisão disse respeito à escolha do primeiro diretor do órgão. O nome definido acabou sendo o do então diretor do Museu Nacional Edgard Roquette-Pinto, médico, antropólogo, escritor e introdutor da radiodifusão no Brasil. Imediatamente após assumir a função, este convidou Humberto Mauro para integrar a equipe, cineasta brasileiro de maior renome na época e que havia se tornado conhecido nacionalmente após integrar o chamado Ciclo de Cataguases (SOUZA, 2001: 163 e 164).

A dupla Roquette-Pinto-Humberto Mauro, formada, de um lado, pelo diretor do INCE e locutor de alguns filmes e, de outro, pelo cineasta e roteirista, mostrou-se com bastante sintonia, o que ajuda a explicar grande parte do sucesso alcançado pelo INCE. O órgão, de 1936 a 1941, funcionou em uma das salas de um prédio localizado no número 45 da Rua da Carioca, no centro da cidade do Rio de Janeiro. Sua equipe era formada por aproximadamente 10 pessoas, incluindo os dois nomes já citados, secretários, técnicos de educação e de laboratório. O grupo de trabalho fazia todos os processos: roteiro, filmagem, revelação, edição, sonorização, cópia e distribuição dos filmes entre as escolas interessadas (SOUZA, 2001: 165 e 166). O orçamento disponível era minguado, o que exigia dos funcionários certa dose de criatividade e de improviso, conforme atesta o depoimento de Roberto Assumpção de Araújo, um ex-secretário do INCE, ao revelar um pouco do cotidiano das atividades desenvolvidas ali:

(...) todo mundo fazia tudo. Eu, por exemplo, saía para a rua com microfone, ia fazer 7 de Setembro - o Mauro e eu. Aí, fazíamos Academia Brasileira de Letras. E o Instituto de Cinema Educativo - ia todo mundo lá: Taunay, Lúcia Miguel Pereira, Gilberto Freire, Mário de Andrade - era um centro de coisas. O Roquette era uma figura. Todo mundo ganhava muito pouco, mas vivia realmente entusiasmado com aquilo. Não havia hora. Fazia-se tudo ali. Revelação, laboratório. Mas



(PPGHIS/UnB) No. 33, Brasília, Ago - Dez 2018 ISSN 2316-1191 
tudo altamente precário (...). E aparecia lá, por exemplo, o Carlos Chagas Filho. Ia fazer um filme chamado Puraquê e chegou lá com o peixe. Tudo era improvisado, mas não havia dificuldades. O que precisasse fazer fazia-se. Então armou-se uma tina e veio o tal puraquê. O puraquê...você começava a mexer e dava corrente elétrica. E o dr. Roquette: “Mas que diabo, cadê a corrente elétrica?”. No dia seguinte, pegou uma vara e começou a cutucar o peixe com a vara, e naturalmente o peixe começou a dar. Ele não dava corrente elétrica a não ser cutucado. Quer dizer, as coisas eram feitas assim. (...) era um estudiozinho onde se fazia Machado de Assis, Vicente de Carvalho, Bandeirantes - tudo se fazia ali... (...) realmente um salon, um lugar onde as pessoas iam porque de cinema todo mundo gosta: filmar, tirar retrato. Ao mesmo tempo que documentava (SOUZA, 2001: 166 e 167).

Apesar dos obstáculos, o INCE foi bastante produtivo. Sheila Schvarzman divide o órgão em dois períodos. No primeiro deles, de 1936 a 1946, caracterizado pela direção de Roquette-Pinto e pelo ministério de Gustavo Capanema (este encerrado em 1945), foram realizados 244 filmes. Ao analisar os temas de cada um deles, a autora chega à conclusão de que produções de caráter científico predominaram: "Divulgação técnica e científica” (38 filmes), “Pesquisa Científica Nacional” (34 filmes) e "PreventivoSanitário” (23 filmes). Ainda se pode ligar à ciência películas que se aproximaram do tema "Riquezas naturais do Brasil” (10 filmes), em que a morfologia de plantas e peixes, por exemplo, é apresentada. Um outro grupo de produções se associa à categoria de “Locais de interesse” (30 filmes), marcado pela divulgação de aspectos paisagísticos, turísticos ou históricos. Além desses, obras cinematográficas foram consideradas “Oficiais” (28 filmes), por tratarem de eventos cívicos e políticos. Em seguida, aquelas voltadas à "Reportagem” (16 filmes), às “Atividades econômicas” (16 filmes) e aos "Vultos nacionais” (12 filmes). Há ainda "Cultura popular e folclore” (9 filmes). Por fim, as câmeras do INCE também foram mobilizadas para assuntos como "Educação física" (9 filmes), “Artes aplicadas” (6 filmes), “Escolar” (5 filmes) e "Meio rural” (4 filmes). A autora não conseguiu categorizar alguns em um grupo específico, então chamou de “Outros” (4 filmes) (SCHVARZMAN, 2004: 381).

Roquette-Pinto esforçou-se para que os filmes do INCE fossem assistidos pelo maior número possível de pessoas, tivessem alcance nacional e chegassem a todos os municípios. Para isso, estimularam-se exibições nas escolas, no auditório do INCE, nos cinemas, em instituições culturais, em agremiações e em exposições. No entanto, houve dificuldades significativas para se alcançar a meta traçada pelo diretor. A distribuição no Rio de Janeiro ocorreu sem maiores problemas, com as escolas retirando as fitas em

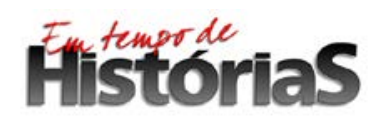

(PPGHIS/UnB) No. 33, Brasília, Ago - Dez 2018 ISSN 2316-1191 
sistema de empréstimo ou fornecendo um filme virgem em troca de uma cópia com a película escolhida, entre as disponíveis no catálogo da instituição. No entanto, quanto mais a escola fosse afastada da capital, mais dificuldades para obter os filmes. Em relatório de 1942, enviado ao Ministério da Educação e Saúde, o diretor do INCE informou que até 31 de dezembro de 1941 haviam sido atendidos cerca de mil trezentos e cinquenta escolas e institutos de cultura, perfazendo mais de três mil e quinhentas projeções. No documento, é possível perceber como os estados da região sudeste acabaram privilegiados, recebendo uma quantidade muito maior de películas quando comparados aos de outras regiões. Por exemplo, enquanto Distrito Federal e Minas Gerais receberam, respectivamente, 90 e 21 filmes, Bahia e Goiás, obtiveram, respectivamente, apenas 3 e 1. Tudo isso demonstra uma limitação do alcance do projeto (ROSA, 2002: 39-42).

Ao longo de sua trajetória, o INCE produziu filmes como Os Inconfidentes (1936), Os músculos superficiais do corpo humano (1936), Termômetros (1937), Victória Régia - Horto Botânico do Museu Nacional (1937), O Dia da Bandeira II (1938), Febre amarela - o preparo da vacina pela Fundação Rockfeller (1938), Um apólogo Machado de Assis. 1839-1939 (1939), O Puraquê - Peixe elétrico (1939), Da força hidráulica à energia elétrica (1940), Parada da Juventude - setembro de 1940 (1940), Cerâmica artística do Brasil - Itaipava (1941), Movimentos protoplasmáticos na célula vegetal (1941), Carlos Gomes - O Guarani - Ato $3^{\circ}$ - Invocação dos Aimorés (1942), Museu Imperial de Petrópolis (1942), Índios do Mato Grosso (1943), Jardim Botânico do Rio de Janeiro (1943), Barão do Rio Branco - 1845/1912 (1944), Exposição de Orquídeas (1944), Aspectos do sul de Minas (1945) e Canções populares I (1945). Em alguns momentos, o órgão desenvolveu películas de 35 milímetros com maior metragem, muitas vezes chegando a quase uma hora de duração, para serem projetadas comercialmente. Assim, o dinheiro obtido com os direitos de exibição se converteria em mais uma fonte de renda para aumentar o orçamento disponível, sempre exíguo. $O$ segredo das asas é um dos melhores exemplares desse gênero.

3- História, personagens e atores de O segredo das asas

Em 12 de dezembro de 1943, o jornal do Rio de Janeiro A Noite anunciou, em uma de suas matérias, a produção em andamento de um novo filme nacional, elaborado




nos laboratórios do Instituto Nacional de Cinema Educativo com o intuito de servir aos esforços de guerra: O segredo das asas. Segundo o periódico, a película representava mais um estímulo desse órgão e do governo para alcançar o progresso do cinema brasileiro. Colaborando com eles, a publicação divulgou aos leitores a novidade, explicando o tema daquela obra cinematográfica e inserindo cinco imagens externas extraídas do filme (A NOITE, 1943: 3). A reprodução dessas cenas foi disponibilizada de modo a despertar a curiosidade e estimular o desejo de todos em frequentar as salas de cinema assim que o material finalizado estivesse disponível para exibição. Com a mesma intenção, a revista A Cena Muda, aproximadamente um mês antes, produzira também um artigo, divulgando o tema e cenas do novo filme. Ao final dele, o redator defendeu a necessidade de que as obras “de elevado espírito de brasilidade” desenvolvidas pelo INCE alcançassem divulgação mais ampla em todos os cinemas do país, uma vez que nem sempre obtinham a difusão necessária e merecida (A CENA MUDA, 1943: 20 e 21).

No início de 1944, jornalistas do periódico A Manhã fizeram uma visita às instalações do Instituto Nacional de Cinema Educativo, localizadas nesse momento na Praça da República. O objetivo era o de reunir informações sobre a história da instituição para a redação de uma matéria, a qual acabou publicada em 16 de fevereiro. Nela, os funcionários do jornal descreveram o tour que fizeram por aquele ambiente, tendo o próprio Humberto Mauro como guia. Em determinado momento, o cineasta convidou-os a adentrarem o estúdio de filmagens, no qual estavam acontecendo as gravações das cenas internas de duas grandes produções, sendo uma delas justamente $O$ segredo das asas ( $A$ MANHÃ, 1944: 3 e 6). Finalmente concluído alguns meses depois, esse filme, um docudrama de média-metragem, em trinta e cinco milímetros, com duração de quarenta e cinco minutos, foi lançado em 13 de junho (PERDIGÃO, 1967: 16).

A Cinemateca Brasileira possui uma ficha com informações técnicas da obra. Por intermédio dela, é possível saber que o pré-lançamento da película ocorreu na Escola de Aeronáutica, no Campo dos Afonsos, Rio de Janeiro. Há também um registro da exibição em São Paulo no cinema Pedro II, do dia 22 a 28 de janeiro de $1945 .^{8}$ A consulta aos jornais da época permitiu identificar o anúncio de exibição dessa produção cinematográfica em dois cinemas de Curitiba, em fevereiro de 1945. O América anunciou para domingo “O maior filme nacional - O SEGREDO DAS ASAS, com Lídia Matos e

8 A ficha pode ser consultada pelo site da instituição, em sua base de dados: http://www.bases.cinemateca.gov.br.




Celso Guimarães” (O DIA, 1945: 6). Já o Opera divulgou da seguinte maneira as sessões às 14h e às 20h: "Produção brasileira magnífica com Lídia Matos, Celso Guimarães e o concurso da orquestra da Banda e dos Cadetes da FAB” (DIÁRIO DA TARDE, 1945: 6).

Toda a equipe de produção e de atuação mobilizada para a película já tinha bastante experiência na execução de outros filmes educativos do mesmo órgão. O roteiro, de autoria de Humberto Mauro, foi baseado em uma peça em verso de mesmo título elaborada pela jornalista e escritora Maria Eugênia Celso, uma constante colaboradora do projeto desenvolvido pela instituição. Aliás, outra produção literária da mesma autora, dessa vez um conto, já havia servido de base para a filmagem de $O$ despertar da redentora. Nessa obra cinematográfica do INCE, lançada em 1942, ela aparece inclusive atuando, ao apresentar e narrar a estória do episódio em que a princesa Isabel, com 16 anos, teria se conscientizado do problema da escravidão no Brasil e se comprometido a providenciar, quando pudesse, a abolição da escravatura. ${ }^{9}$ Por sua vez, além da contribuição de Humberto Mauro, a parte técnica da fotografia e da montagem ficou a cargo de Manoel Ribeiro, autor das imagens muito elogiadas e consideradas de beleza cênica de filmes como Argila (1940), Descobrimento do Brasil (1937) e Bandeirantes (1940), todos os três dirigidos por Humberto Mauro, sendo os dois últimos para o INCE (A NOITE, 1943: 3).

Por fim, o elenco, composto de três atores, a saber, Celso Guimarães e Lídia Matos, protagonistas, e Lígia Sarmento, coadjuvante, provinha do rádio. Havia se tornado comum no final dos anos 1930 e início dos 1940, com a produção mais frequente dos filmes nacionais, que artistas de rádio estrelassem películas emprestando parte do seu prestígio e sucesso à sétima arte, fazendo com que frequentemente imensas filas se formassem junto às salas de projeção (SALVADOR, 2010: 215). ${ }^{10}$ Celso Guimarães foi locutor da Rádio Nacional e também ator e galã das radionovelas da mesma emissora, e Lídia Matos e Lígia Sarmento eram atrizes de radionovelas. Além disso, os dois atores principais de $O$ Segredo das Asas já haviam colaborado em outros projetos de Humberto Mauro, como no filme Argila (FOLHA DE SÃO PAULO, 1997: 5). Especificamente para

\footnotetext{
9 Para ter acesso ao filme $O$ despertar da redentora, consultar o Banco de Conteúdos Culturais da Cinemateca Brasileira, por meio do seguinte link: http://www.bcc.org.br/filmes/449534.

${ }^{10}$ Uma das principais razões para o aumento significativo do número de filmes nacionais nesse período deve ser atribuída à chamada "lei do short", após a regulamentação do Decreto n ${ }^{\circ} 21.240$, de 4 de abril de 1932, publicada no Diário Oficial em 1934, a qual determinou a exibição obrigatória de um filme brasileiro de curta-metragem em todas as sessões de cinema existentes no Brasil (SOUZA, 2001: 158 e 159).
} 
o INCE, Lídia Matos tinha interpretado a princesa Isabel, personagem principal de $O$ despertar da redentora. Já Celso Guimarães, como locutor, narrou o filme Serpentes do Brasil, documentário de curta-metragem, lançado em 1941, com duração de seis minutos. ${ }^{11}$

Após esses dados mais técnicos, resta introduzir nesta narrativa a sinopse do filme. ${ }^{12}$ Na película em questão, a estória é ambientada na cidade do Rio de Janeiro. Celso Guimarães faz o papel de um piloto de avião, tipo de personagem o qual já havia encarnado no cinema em duas produções anteriores: Asas do Brasil, de 1940, película não concluída devido à destruição de seu material pelo incêndio da Sonofilmes, mas refilmada em 1948, e Caminho do Céu, de 1943, desenvolvida pela Cinédia. Por tal coincidência, o ator chegou a ser chamado pela revista A Cena Muda de "intérprete oficial de aviador nos filmes brasileiros” (A CENA MUDA, 1943: 20 e 21). Lídia Matos representa Maria, uma jovem paralítica, o que cenicamente é demonstrado pelo par de muletas próximo à cadeira na qual fica sentada o tempo todo. Ela trabalha como rendeira em casa, propriedade localizada ao redor do pasto de uma roça. Enquanto exerce na sala seu ofício, observa cotidianamente pela janela o céu e os aviões que por lá passam, alguns deles de propriedade militar, da Escola de Cadetes da Aeronáutica, cujos pilotos, aproveitando-se da proximidade do Campo dos Afonsos com o local, sobrevoam-no para fazerem exercícios e treinamentos. Por fim, a atriz Lígia Sarmento atua como tia Antoninha, costureira, de quem Maria é sobrinha.

Imagem 1: As atrizes Lígia Sarmento e Lídia Matos em cena de O segredo das asas

\footnotetext{
${ }^{11}$ Tal obra cinematográfica apresenta exemplares característicos de serpentes encontradas no Brasil, como a cobra-cipó e a sucuri. Além disso, retrata o trabalho desenvolvido no Instituto Butantã, em São Paulo, no qual uma grande diversidade de espécies é utilizada para estudo e retirada do soro antiofídico. Ela também está disponível no Banco de Conteúdos Culturais da Cinemateca Brasileira: http://www.bcc.org.br/filmes/443491.

12 A sinopse aqui descrita foi elaborada com base na visualização do filme, disponível no Banco de Conteúdos Culturais da Cinemateca Brasileira: http://www.bcc.org.br/filmes/443372.
} 




Fonte: http://www.bcc.org.br

O filme começa com a tia avisando para a personagem de Lídia Matos que daria uma saída, mas voltaria logo. Como de costume, a moça inicia o trabalho com a renda, ao mesmo tempo em que espia o lado de fora, aguardando a companhia diária dos aviões que "não a deixam ficar só”, conforme a fala da jovem: "Eu, estando à janela, estou sempre acompanhada”. Após algum tempo, surge no horizonte uma aeronave, que, como das outras vezes, põe-se a praticar manobras na região. Maria logo ouve o ronco do motor e passa a acompanhar alegre o trajeto do aparelho aéreo. No entanto, diferentemente das outras vezes, ela estranha o voo baixo, próximo ao chão. Aflita, percebe que o piloto enfrenta problemas, que o fazem optar por um pouso de emergência no pasto da roça. Em seguida, identificando uma avaria séria no rádio, ele desce do aparelho aéreo, caminha até a casa, na qual é recebido pela protagonista, que o convida a entrar. Sem um telefone na propriedade e nas imediações ou alguém que levasse um recado, para comunicar à Escola de Aeronáutica do pouso forçado, resta ao aviador aguardar que um colega do Campo dos Afonsos fosse procurá-lo e resgatá-lo.

Enquanto isso, o personagem de Celso Guimarães, percebendo a admiração e a curiosidade que a moça demonstra pela aviação e pelos profissionais da área, passa a conversar com ela sobre o assunto. Maria conta que vive sempre perto da janela, porque, além de fornecer mais luz para auxiliar no seu trabalho, pode ver os aviões que passam.

\section{Filistororias}


Ao não ter outra distração além de rendar, já que não pode sair, pela necessidade do uso de muletas, a janela tornou-se a sua vida: “tudo o que há de belo é dela que me vem. Às vezes, o céu está tão iluminado, tão transparente, tão claro, que eu fico a imaginar o que deve ser a delícia de voar”. Prontamente, o piloto tenta descrever a sensação: “É mais que uma delícia, é um prazer diferente, uma volúpia santa”. E conclui sua reflexão justamente apresentando o mote do filme: "Ser aviador: o segredo das asas”. Fascinada por tudo, a moça indaga: “Como é esse segredo? Como se aprende, hein? A escola deve ser bonita!”. Percebendo o entusiasmo dela, o aviador passa a explicar com detalhes o cotidiano da formação dos pilotos militares. Nesse momento, as cenas ficcionais na casa da rendeira, e gravadas em estúdio, dão lugar a imagens externas, e o filme transforma-se em um documentário, narrado por Celso Guimarães. Nele, o personagem militar conta à moça a respeito da criação, localização e funcionamento da Escola de Aeronáutica.

Imagem 2: Os atores Celso Guimarães e Lídia Matos em cena de O segredo das asas

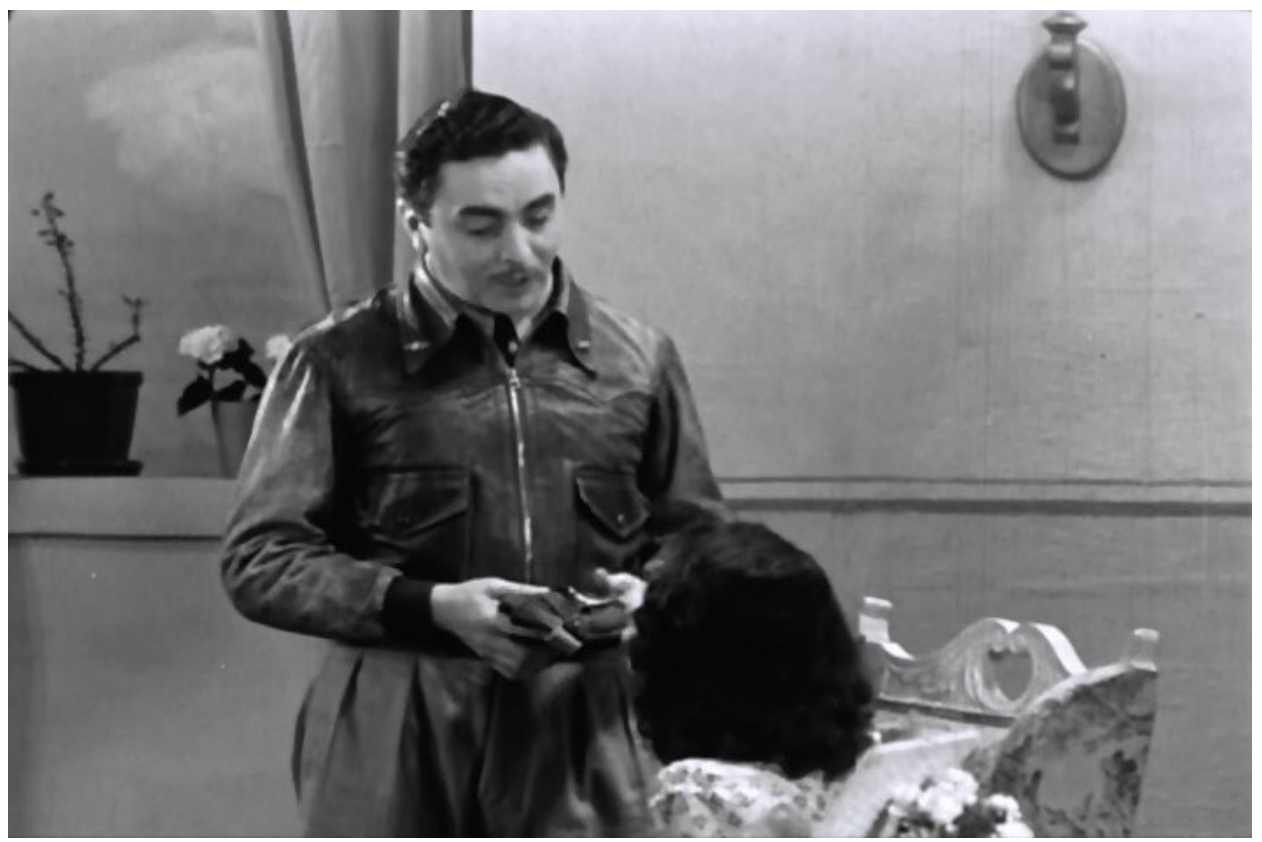

Fonte: http://www.bcc.org.br

4- O segredo das asas como mais um elemento do projeto de construção de uma mentalidade aeronáutica

\section{Filistororias}


O que se pretende demonstrar neste artigo é que o filme em questão não foi criado pelo INCE como uma simples contribuição do órgão aos esforços gerais de guerra e como uma demonstração patriótica de que o Brasil estava preparado para enviar tropas à Itália, produzindo confiança na população em um momento no qual se denunciavam ouvir “vozes derrotistas” (BARROS, 2010: 64; SCHVARZMAN, 2004: 230). Mais do que isso, a elaboração de uma obra cinematográfica cujo tema é a aviação deve ser compreendida também e principalmente enquanto uma ação específica de colaboração do Ministério da Educação e Saúde com o projeto de construção de uma mentalidade aeronáutica desenvolvido por Salgado Filho. Na verdade, a contribuição do INCE no plano da Aeronáutica, de difusão de tudo o que se referia à aviação, já havia rendido outros frutos no mesmo ano de 1944, como são bons exemplos os seguintes filmes também do órgão de cinema educativo: Fabricando motores de Aviação e Escola Técnica de Aviação de São Paulo, ambos de dezesseis milímetros (DIÁRIO CARIOCA, 1945: 8).

Esses dois filmes, somados a $O$ segredo das asas, representavam em suas temáticas justamente as três grandes metas traçadas pelo ministro da Aeronáutica na frase que sintetizou os principais direcionamentos de sua administração: "Pilotos para o Brasil, aviões para os pilotos e técnicos para os aviões. Esta é a flâmula aeronáutica”. Enquanto Fabricando motores de Aviação contribuiu para divulgar o que o governo estava fazendo para produzir mais peças e aviões e, assim, permitir a futura autonomia brasileira na área, Escola Técnica de Aviação de São Paulo demonstrou o empenho do Estado Novo em ampliar o quadro de profissionais técnicos da Aeronáutica, a saber, de oficiais das especialidades de fotógrafo e de mecânico de avião, de rádio ou de armamento, desenvolvendo em outro estado mais um local de formação, antes concentrado apenas no Rio de Janeiro, com a Escola de Especialistas de Aeronáutica. Completando a tríade, pilotos, aviões e técnicos, $O$ segredo das asas se destinou principalmente a divulgar as ações em prol da formação de pilotos militares e a estimular jovens que o assistissem a optarem por integrar os quadros da mais recente força armada instituída, tornando-se a reserva aérea de que o Brasil precisava no contexto tanto de entrada do país na Segunda Guerra quanto de envio de tropas à Europa.

Na coluna publicada no dia 23 de abril de 1944, em O Jornal, repercutindo a utilização de sua peça $O$ segredo das asas como base e referência para o roteiro do filme desenvolvido por Humberto Mauro, Maria Eugênia Celso explicou aos leitores que o principal conceito poético que a inspirou a escrever o enredo baseou-se em uma 
observação cotidiana da realidade: “quando no azul de um céu meridiano um pássaro de aço rebrilhante passa a zumbir. Todos os olhos se alçam instintivamente. Há um excelsior inconsciente em todas as atenções” (CELSO, 1944: 3). Ou seja, para ela, o avião havia criado uma mística do voo. Essa é justamente a principal questão presente na peça e, consequentemente, no filme do INCE. A personagem Maria era imbuída, nas duas produções, desse sentimento, pois as aeronaves que passavam por sua janela sempre despertavam fascinação e magnetismo nos olhos dela. Justamente essa mística, “a que milhares e milhares de rapazes, em todos os cantos do mundo, se entregam de corpo e alma, num transporte de entusiasmo irresistível”, tem servido para a aeronáutica arregimentar mais jovens para as suas fileiras, em um "admirável voluntariado do ar" (CELSO, 1944: 3).

A peça de Maria Eugênia Celso, ato em duas cenas, ao que tudo indica, nunca chegou a ser montada, mas foi publicada em 1931 no livro Ruflo de Azas, junto com outros dois textos teatrais da autora. ${ }^{13}$ A leitura da obra revela que Humberto Mauro utilizou grande parte da estrutura narrativa original, valendo-se dos mesmos três personagens, do cenário, do problema no avião que levou o piloto a manter conversa com Maria e de uma parte dos diálogos. ${ }^{14}$ A grande diferença de uma produção para outra reside no trecho em que o aviador conta sobre o cotidiano de formação dos cadetes da Escola de Aeronáutica do Campo dos Afonsos, inexistente na peça e central no filme. Portanto, o fragmento da obra cinematográfica em formato de documentário é a grande contribuição autoral de Humberto Mauro em O segredo das asas. É preciso estar atento ao contexto distinto em que as duas produções foram pensadas: a peça, quando a aviação brasileira ainda era desmembrada sob o controle de três ministérios distintos; e o filme, quando o Ministério da Aeronáutica, criado em janeiro de 1941, já havia unificado todas as aviações, e o aparelho aéreo despontava como fundamental para a vitória na Guerra.

A comparação entre os dois produtos culturais e a identificação da parte que os diferencia tornam ainda mais nítido o interesse de Humberto Mauro em utilizar a película com o intuito de promover o fortalecimento da construção de uma mentalidade aeronáutica e de arregimentar jovens para a carreira da aviação militar. Esse objetivo

\footnotetext{
${ }^{13}$ Nesses outros dois textos publicados em Ruflo de Azas, Amores de Abat-jour e Por causa d'Ella..., há a informação da data e do local de encenação. Como essa informação não foi disponibilizada para $O$ segredo das asas, indica que a peça sobre a aviação não havia sido montada.

${ }^{14}$ Uma pequena diferença a ser destacada é a de que na peça Antoninha é irmã de Maria e no filme é tia.
} 
também ficou explícito no comentário que ele fez durante apresentação de uma atração de rádio. Semanalmente, ao longo de um ano, o cineasta apresentou o programa Figuras e gestos, na PRA-2, rádio do Ministério da Educação e Saúde, no qual desenvolveu, de 1943 a 1944, 48 palestras sobre questões relativas ao cinema. Naquela irradiada em 06 de maio de 1944, às 22h, o funcionário do INCE aproveitou o espaço para tecer alguns comentários a respeito do filme $O$ segredo das asas, informando aos ouvintes que "o documentário mostra, nos seus mínimos detalhes, como se formam os oficiais aviadores para a Força Aérea Brasileira, que é o único objetivo da Escola” (MACIEL, 2000: 181).

Como esse projeto do órgão de cinema governamental se mostrava uma política cultural de grande importância para a construção de uma mentalidade aeronáutica, no geral, e de estímulo à formação de futuros pilotos, em particular, a Pasta de Salgado Filho colaborou diretamente com a iniciativa. O INCE já tinha experiência na produção de películas produzidas em parceria com outros setores da administração governamental, inclusive ministeriais, sendo o melhor exemplo a execução e lançamento, também em 1944, do filme Barão do Rio Branco - 1845/1912, sobre a biografia do diplomata José Maria da Silva Paranhos, elaborado com a ajuda direta do Ministério das Relações Exteriores. Em seu programa de rádio, Humberto Mauro fez questão de destacar como imprescindível para o sucesso da empreitada a associação entre o órgão no qual trabalhava e o ministério que controlava a aviação: “O INCE contou também com a preciosa colaboração da Escola de Aeronáutica do Campo dos Afonsos. Graças à boa vontade do seu comandante, coronel Fontenelle, dos oficiais e cadetes, o INCE teve à sua disposição todos os elementos necessários para uma documentação completa da Escola” (MACIEL, 2000: 181). Essa parceria já havia sido inclusive registrada nos créditos iniciais da obra, os quais informam também a presença nela de marchas e canções executadas pela banda de cadetes da Escola de Aeronáutica. Não à toa, o pré-lançamento da película, como já informado, ocorreu no próprio Campo dos Afonsos.

Já tendo sido apresentada uma espécie de sinopse do filme, neste momento o foco da análise recairá principalmente na parte da película que não tem relação direta com a peça de Maria Eugênia Celso. Ou seja, aquela constituída por um documentário, em que o personagem interpretado por Celso Guimarães revela à rendeira os detalhes de todas as etapas de formação do aviador militar, desde a chegada à escola até a formatura. Justamente o percurso que configurava o transcurso gradual do vir a ser um piloto e do aprimoramento dos elementos que permitiam a cada um que ali se instruísse dominar, ao

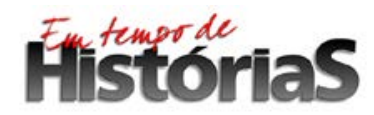


final do processo, o "segredo das asas", justamente o mote central da obra cinematográfica. Esse pedaço mostra-se fundamental para se compreender de que maneira o filme colaborou diretamente com a construção de uma mentalidade aeronáutica e com o incentivo à adesão de mais jovens à profissão de aviador.

O documentário se inicia com imagens do Campo dos Afonsos, a entrada, na qual se focaliza o Monumento ao Aviador; a pista de treinamento; os hangares; aviões aguardando a decolagem; alunos da Escola de Aeronáutica praticando exercícios físicos; imagens de uma biruta instalada no alto de uma torre, indicando a direção do vento; e tomadas panorâmicas feitas de um avião, que dão uma visão geral sobre as instalações daquele complexo voltado às atividades de aviação. Enquanto as imagens são exibidas, Celso Guimarães narra, tendo sempre ao fundo o som de execução da melodia do Hino Nacional, um pequeno histórico das escolas de aviação no Brasil. A fala informa desde a fundação da primeira, em novembro de 1914, até as transformações ocorridas após a criação do Ministério da Aeronáutica e a fundição de todos os serviços aeronáuticos do país. Inclusive, há referência à Escola de Aviação Naval e à Escola de Aviação Militar, que deram origem a então atual Escola de Aeronáutica, em 25 de março de 1941. Depois, acrescenta, ainda, detalhes da sede atual, como o tamanho, área de 40 mil metros quadrados, considerada grande, o tipo de arquitetura e o nome dos primeiros comandantes.

Em seguida, todo o texto escrito por Humberto Mauro, para ser lido por Celso Guimarães, é estruturado de modo a enfatizar que a Escola, após as mudanças decorrentes da unificação proporcionada pela criação do Ministério da Aeronáutica, estava baseada nas mais modernas e eficientes técnicas de seleção e de ensino, disponíveis mundialmente, não diferindo daquelas adotadas pelas principais nações do mundo. De modo a confirmar isso, a película apresenta imagens de testes físicos e psicológicos aplicados na escolha dos candidatos, para demonstrar como apenas os mais qualificados permanecem na corporação, desde que se mostrem aptos em testes rigorosos regularmente aplicados. Ao fundo da narração, o Hino Nacional permanece sendo constantemente executado. Logo, o Gabinete de Fisiologia aparece na tela, ambiente no qual os candidatos se submetem a exame biométrico, prova funcional respiratória e prova funcional circulatória. Esta última, destaca com entusiasmo o narrador, é um método essencialmente brasileiro e tem se mostrado superior a quaisquer outros empregados em países estrangeiros. 
Ainda apresentando os testes de habilitação, são reveladas ao público as instalações de radiologia e de exame de vista, bem como o Gabinete de Psicologia, no qual são feitos os exames de habilidade manual, sensação, memória, senso crítico e todas as funções intelectuais e afetivas. Para auxiliar no equilíbrio físico e mental do futuro aviador, o filme destaca também a importância da seção de Educação Física, que “dará ao cadete energia suficiente para enfrentar todos os esforços que lhe serão solicitados como piloto militar”. Enquanto ocorre a narração, são exibidas imagens da prática, entre outras, de corrida, salto, natação, arremesso de peso e lançamento de dardo. A execução das atividades esportivas é sempre mostrada como exercida com muita ordem e disciplina. Exatamente dessa maneira, marchando em um bloco coeso, os cadetes são filmados se dirigindo ao pavilhão de Aerotécnica Militar, no qual os futuros oficiais estudam o funcionamento do avião e dos componentes dele, ficando aptos a verificar o funcionamento e fazer a manutenção, o que os qualificava a dirigir qualquer oficina de material aeronáutico. Há o estudo de hélices, trens de pouso, processos de soldagem, carpintaria e a familiarização do futuro aviador com “o seu melhor amigo: o motor”.

Em seguida, percebendo o olhar de atenção e de admiração estampado no rosto de Maria, o aviador começa a contar para a rendeira sobre os três estágios pelos quais o cadete obrigatoriamente precisa passar para se tornar um oficial. No estágio primário, ocorre o início da instrução de pilotagem, quando o aluno efetua pela primeira vez o voo sozinho, considerado pelo narrador “o momento mais emocionante da vida de um piloto”. No segundo estágio, básico, o cadete entra em contato com aviões mais avançados e aprende pilotagem sem visibilidade (o voo cego), reconhecimento de território, regulação de tiro, patrulhamento e utilização do rádio. Para este último, é indispensável a torre de rádio, que controla e transmite as instruções e ordens para o pouso e a decolagem. Por fim, no último estágio, avançado, o cadete é liberado a usar aviões de guerra, fazendo o manejo das metralhadoras, dos aparelhos de pontaria e da alça de bombardeio.

É preciso destacar que as imagens sempre vão ilustrando exatamente aquilo que é narrado por Celso Guimarães. Esperava-se justamente que os dois recursos juntos encantassem a plateia do cinema da mesma forma que Maria se mostrava fascinada na película. Além disso, almejava-se que uma parte da audiência, mobilizada pelo que viu na tela, descobrisse-se imbuída de vocação por tal profissão. Após a explicação dos estágios, o filme deixa momentaneamente o formato de documentário e volta a exibir o cenário da casa da rendeira. O personagem do aviador, para concluir a explicação, põe-se 
a contar sobre o tão esperado dia da festa de formatura, do juramento: ocasião em que o presidente da República passa em revista toda a escola. Um close no rosto de Maria, admirada e sorrindo tentando visualizar a cerimônia, é a estratégia empregada para o filme voltar ao documentário. Cenas de Getúlio Vargas e de Salgado Filho chegando ao Campo dos Afonsos e protagonizando o evento são apresentadas. O ângulo de uma tomada da câmera focaliza bem as bandeiras do Brasil e dos Estados Unidos, hasteadas lado a lado, demonstrando os esforços conjuntos na guerra.

A câmera volta ao ambiente da casa, para que o aviador conte à moça a respeito da cerimônia de um minuto de silêncio em homenagem aos companheiros que morreram durante o curso. Logo, retorna ao documentário, apresentando imagens do referido ritual. De volta ao cenário montado nos estúdios do INCE, o personagem de Celso Guimarães conta à rendeira sobre o juramento e a entrega dos brevês. Novo close no rosto da atriz Lídia Matos sorrindo emocionada e volta ao documentário para ver as respectivas cenas. Nessa parte, o áudio de um militar pronunciando em partes o texto do juramento e a sua repetição pelos aspirantes a oficial aviador é ouvido, mas as imagens são dos rostos do piloto e de Maria, emocionados com essa etapa final da formação. Assim que o personagem de Celso Guimarães encerra a descrição, ouve-se o som de uma aeronave aproximando-se da casa próxima à roça. Trata-se de um colega do Campo dos Afonsos que localizou o aparelho pousado. O piloto despede-se, mas promete que todas as vezes nas quais saísse da Escola para treinamento daria uma volta de avião até lá para ver do alto a janela da rendeira. Na cena final, ele cumpre a promessa e passa com uma esquadrilha por sobre a casa de Maria, que sorri emocionada e acena para o grupo, enquanto ao fundo vozes cantam o Hino Bandeirantes do Ar, no qual uma das estrofes apresenta os seguintes versos: “Nós somos da Força Aérea Brasileira/Nosso emblema é a águia altaneira/Que há de ser grande, forte e varonil!/Lutaremos, morreremos/Pela bandeira do Brasil!/Lutaremos, morreremos/Pela bandeira do Brasil!”.

Imagem 3: Cerimônia de juramento e de entrega dos brevês

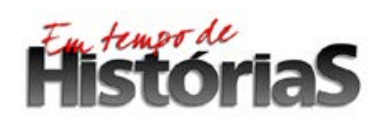




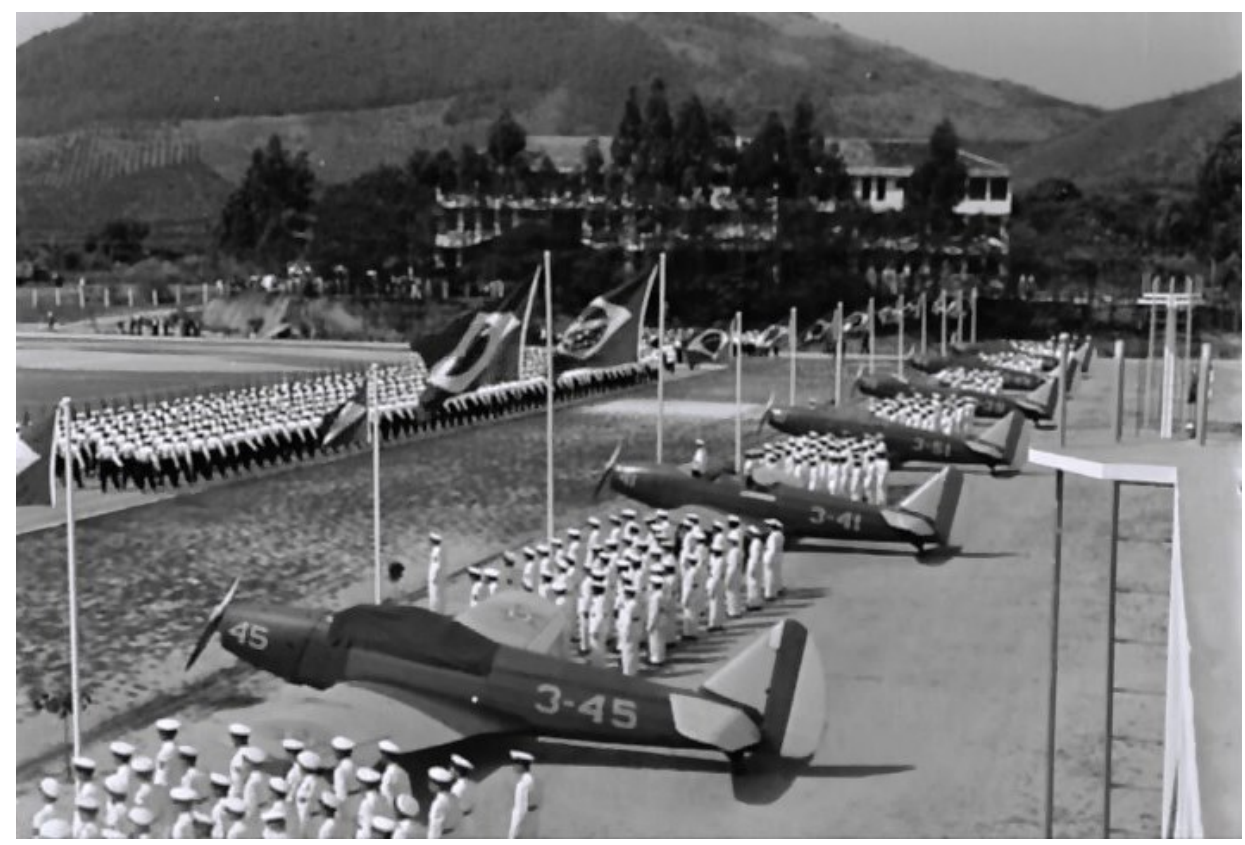

Fonte: http://www.bcc.org.br

Por fim, duas falas do aviador em conversa com a rendeira revelam o principal argumento do filme. A primeira aparece no início do diálogo entre os protagonistas: “Um avião que passa arrasta sempre um pouco a alma da gente”. A segunda fecha o contato entre os dois personagens: "Não é só avião que tem asas, Maria. As asas do coração alcançam na altura todos os aviões”. Após essa segunda colocação, a personagem de Lídia Matos fica reflexiva e emocionada. Em seguida, um mapa da Europa mostra a guerra em andamento, manchetes de jornal documentam o afundamento de navios brasileiros por submarinos alemães e a entrada do país no conflito, o que mobilizou um esforço ainda maior dos aviadores para protegerem a nação. Ou seja, a introdução de frases como essas tinha por intenção a constante reafirmação aos brasileiros da necessidade do reconhecimento de todo o sacrifício a que os pilotos militares estavam se sujeitando. A máxima era a de incentivar a população a colaborar de todas as formas com o setor, o que seria alcançado com uma identificação não apenas racional, mas sobretudo sentimental, fazendo a causa ocupar tanto as mentes quanto os corações.

\section{5- Conclusão}

\section{Filstororias}


Este artigo procurou mostrar que diante da centralidade alcançada pelo avião no Brasil, nos anos 1940, o Instituto Nacional de Cinema Educativo (INCE) passou a colaborar diretamente com o projeto governamental de construção de uma mentalidade aeronáutica. Essa associação ocorreu após a criação do Ministério da Aeronáutica e a unificação, conduzida por ele, de todos os órgãos de aviação existentes até então no país. Nesse momento, Salgado Filho buscou, por intermédio de investimentos materiais e simbólicos, públicos e privados, nas esferas civil e militar, generalizar a compreensão e o interesse da população pelo progresso da navegação aérea. Em decorrência disso, várias políticas culturais foram desenvolvidas de modo a fazer o maior número possível de brasileiros unirem-se à causa, sendo a produção do filme $O$ segredo das asas uma delas. Fruto de uma colaboração entre Humberto Mauro, do INCE, e o coronel Henrique Dyott Fontenelle, comandante da Escola de Aeronáutica do Campo dos Afonsos, a película tinha a intenção tanto de revelar aos brasileiros todo o esforço que estava sendo feito para dotar o Brasil de pilotos capacitados a proteger a pátria quanto o de convencer jovens brasileiros a se tornarem futuramente um desses aviadores.

\section{Referências bibliográficas}

A CENA MUDA. O segredo das asas. Rio de Janeiro, 16 de novembro de 1943, n . 46. P. 20 e 21.

A MANHÃ. O cinema é um poderoso instrumento de divulgação da cultura e da educação. Rio de Janeiro, quarta-feira, 16 de fevereiro de 1944. P. 3 e 6.

A NOITE. Segredo das asas. Rio de Janeiro, domingo, 12 de dezembro de 1943. P. 3.

BARROS, Orlando de. A guerra dos artistas: dois episódios da história brasileira durante a Segunda Guerra Mundial. Rio de Janeiro: E-papers, 2010.

CELSO, Maria Eugênia. O segredo das asas. In: Ruflo de Azas. Rio de Janeiro: Livraria Francisco Alves, 1931. Pp. 27-47.

Passa um avião.... O Jornal, Rio de Janeiro, domingo, 23 de abril de 1944. P. 3.

DIÁRIO CARIOCA. A grande atividade do Instituto Nacional do Cinema Educativo. Rio de Janeiro, sextafeira, 5 de janeiro de 1945. P. 8.

DIÁRIO DA TARDE. Curitiba, segunda-feira, 12 de fevereiro de 1945. P. 6.

FOLHA DE SÃO PAULO. Caderno Mais. Humberto Mauro. São Paulo, domingo, 27 de abril de 1997. Pp. 4-7.

FRAGA, André Barbosa. O Brasil tem asas: a construção de uma mentalidade aeronáutica no governo Vargas. Tese de doutorado em História. Niterói: Universidade Federal Fluminense, 2017.

LAVENÈRE-WANDERLEY, Nelson Freire. História da Força Aérea Brasileira. $2^{\mathrm{a}}$ ed. Rio de Janeiro: Editora Gráfica Brasileira Ltda, 1975.

MACIEL, Ana Carolina de Moura Delfim. Figuras e gestos de Humberto Mauro: uma edição comentada. Dissertação de mestrado em Artes. Campinas/SP: Unicamp, 2000.

MOURA, Nero. Um voo na história. Rio de Janeiro: FGV, 1996.

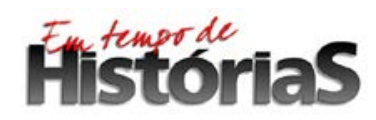

(PPGHIS/UnB) No. 33, Brasília, Ago - Dez 2018 ISSN 2316-1191 
O DIA. Curitiba, terça-feira, 6 de fevereiro de 1945. P. 6.

O RADICAL. Ministério do Ar. Rio de Janeiro, quarta-feira, 11 de dezembro de 1940. P. 4

PERDIGÃO, Paulo. Mauro, diretor: filmografia. Filme \& Cultura, janeiro/fevereiro de 1967, nº 3, Rio de Janeiro, Gráfica Muniz S. A. Editora.

RODRIGUES, Lisias A. Evolução aeronáutica brasileira - Futuro aeronáutico do Brasil. Dos Jornais, ano I, n. 6, novembro. Rio de Janeiro: DIP, 1941. Pp. 75-77.

ROSA, Cristina Souza de. Imagens que educam: o cinema educativo no Brasil dos anos 1930-1940. Dissertação de mestrado em História. Niterói/RJ: UFF, 2002.

SALVADOR, Roberto. A era do radioteatro: o registro da história de um gênero que emocionou o Brasil. Rio de Janeiro: Gramma, 2010.

SCHVARZMAN, Sheila. Humberto Mauro e as imagens do Brasil. São Paulo: UNESP, 2004.

SOUZA, Carlos Roberto de. Cinema em tempos de Capanema In: BOMENY, Helena (org.). Constelação Capanema: intelectuais e políticas. Rio de Janeiro: Ed. Fundação Getúlio Vargas; Bragança Paulista (SP): Ed. Universidade de São Francisco, 2001. Pp. 153-182.

VARGAS, Getúlio. O cinema nacional elemento de aproximação dos habitantes do país. In: A nova política do Brasil. Volume III. Rio de Janeiro: José Olympio, 1938. Pp. 183-189.

VELHO, Gilberto. Projeto e metamorfose: antropologia das sociedades complexas. Rio de Janeiro: Jorge Zahar, 1994. 